\title{
Basics and advanced developments in photocatalysis - a review (Mini review)
}

\begin{abstract}
Intensive research work has been carried out for the degradation of organic pollutants present in the environment using the metal oxide semiconductors. For the same, $\mathrm{TiO}_{2}$, $\mathrm{ZnO}$ semiconductor photocatalysts has been widely used, but the main drawback of these materials is able to utilize the UV spectrum only, due to its high band gap property. Since solar spectrum contain a significant proportion of the visible light, it is imperative that for an active and versatile utilization of the incident solar energy. The visible light active photocatalysts with a relatively smaller band gap are developed. However, smaller band gap often results in rapid recombination and conversion of photonic energy into non-usable heat. The main aim of this review is provide different ways for utilization of solar spectrum using different catalyst with relatively smaller band gap.
\end{abstract}

Volume 2 Issue 4 - 2018

\author{
Yuvaraj M Hunge, ' Anuja A Yadav² \\ 'Department of Physics, Savitribai Phule Pune University, India \\ ${ }^{2}$ Department of Physics, The Institute of Science, India
}

Correspondence: Hunge YM, Department of Physics, Savitribai Phule Pune University, India, Email yuvihunge@gmail.com

Received: July 31, 2018 | Published: August 31, 2018

\section{Introduction}

Presently, world is facing the problem of environmental pollution, which is associated to the air, water and soil pollution. This is mainly due to a continually rising of population and increase of demands for source water. Due to rapid civilization and industrialization, many pollutants such as various toxic compounds, dyes, sulfates are dumped into water. ${ }^{1,2}$ Water is an indispensable source of life. It is the major solvent, for all biochemical processes. The discharged waste water from the industries contains the organic, inorganic and microbial contaminants that are hazardous to human, aquatic and biotic life. The removal of organic contaminants form water is of prime importance. ${ }^{3}$ Degradation of pollutants is of paramount importance as far as potable water is concerned.

There are different methods are used for the degradation of organic pollutants present in the environment, however, among them, advanced oxidation processes (AOP's) has been demonstrated to be effective for the degradation of organic pollutants. It is a useful for complete mineralization of organic pollutants into water and carbon dioxide with the help of highly reactive radicals ( $\mathrm{OH}$ and $\left.\mathrm{O}_{2}^{-{ }^{-}}\right)^{4,5}$ These radicles are highly reactive and unstable because one of the electron is unpaired. By interaction of these radicles with organic pollutants convert hazardous pollutants into less hazardous products. This review focus on the basics of photocatalysis and effective utilization of solar spectrum by doping and preparing the stratified films.

\section{Photocatalysis}

The phenomenon of photocatalysis was first discovered by Honda-Fujishima, which is based on the photo-electrochemical water splitting using titania. ${ }^{6}$ Photocatalytic degradation which come under AOPs that involves interaction of semiconductor material with light and oxygen, water molecules are responsible for the production of radicals. It involves the absorption of photons having energy (hv) equal to or greater than the band gap energy $\left(\mathrm{E}_{\mathrm{g}}\right)$ of a semiconductor material, then there is generation of electron hole pairs. ${ }^{7,8}$ Upon the incident of light on semiconductor, electrons (e) jump from its valence band (VB) to conduction band (CB), thus there is concurrently formation of a hole $\left(\mathrm{h}^{+}\right)$in the valence band (Eq. (1)). But in most of cases the holes and electrons can recombine and discharge the energy in the form of heat (Eq. (2)). These photogenerated $\mathrm{e}^{-}$and $\mathrm{h}^{+}$then react with available oxidants and reductants, respectively, to form unstable radicals (Eqs. (3) and (4)) which further react with the organic pollutant and subsequently mineralize it to carbon dioxide and water, forming a number of intermediate products (Eqs. (5) and (6)). These reactions can be presented as follows ${ }^{1}$

$$
\begin{aligned}
& \text { Semiconductor (photocatalyst) }+h v=e^{-} \mathrm{CB}+h^{+} \mathrm{VB} \\
& e^{-} \mathrm{CB}^{+}+{h^{+}}_{\mathrm{VB}}=\text { Energy }(\text { Heat }) \\
& \mathrm{H}_{2} \mathrm{O}+h^{+} \mathrm{VB}=\mathrm{OH}(\text { Hydroxyl radical })+\mathrm{H}^{+} \\
& \mathrm{O}_{2}+e^{-} \mathrm{CB}=\mathrm{O}_{2}^{-}(\text {Super oxide radical }) \\
& \mathrm{OH}^{+} \text {Organic pollutant }=\text { Intermediate }=\mathrm{CO}_{2}+\mathrm{H}_{2} \mathrm{O} \\
& \mathrm{O}_{2}^{-}+\text {Organic pollutant }=\text { Intermediate }=\mathrm{CO}_{2}+\mathrm{H}_{2} \mathrm{O} \text { (6) }
\end{aligned}
$$

The overall photocatalytic process involves three major steps:

i. Absorption of light by the semiconductor to generate of electronhole pairs,

ii. Charge separation and migration to the surface of the semiconductor and

iii. Surface reaction for the water reduction or oxidation reactions. ${ }^{9}$

Photocatalysis phenomenon is based on the redox reactions take place at the surface of semiconductor material. Chiefly, it is a green root for the mineralization of organic compound present in the environment. It takes oxygen from air and process take place at ambient temperature and pressure. It provides a wide range of applications, notable amongst them being effluent treatment containing organic pollutants and water splitting. In photocatalysis, the photocatalytic activity depends on the ability of the catalyst to create electronhole pairs, which are then taking part in a redox reaction to generate 
hydroxyl, superoxide radicals, which are able to undergo secondary reactions. The main drawback of this process is low efficiency due to recombination of charge carriers. ${ }^{10}$

\section{Different ways of enhancing photocatalytic efficiency}

There are different ways of enhancing photocatalytic efficiency, which are given below

\section{Photoelectrocatalysis}

The enhancement in photocatalytic efficiency is done by applying bias of $1.5 \mathrm{~V}$, which results into separation of photo generated charge carriers and increase the efficiency. Hunge et al. studied the photoelectrocatalytic degradation of terephathalic acid using $\mathrm{ZnO}$ photocatalyst under UV light illumination. ${ }^{11}$

\section{By Doping}

By doping the suitable element. Mohite et al. studied the degradation of benzoic acid using $\mathrm{Au}$ doped $\mathrm{TiO}_{2}$ films and shows that enhancement in degradation efficiency by doping. ${ }^{12}$ Mahadik et al. studied the degradation of phthalic acid using $\mathrm{Al}$ doped $\mathrm{ZnO}$ thin films. ${ }^{13}$

\section{Using Stratified films}

By making the layered films of metal oxide semiconductor for avoiding the recombination and transfer of photo generated electrons and holes Hunge et al, ${ }^{15}$ studied the degradation of oxalic acid using $\mathrm{WO}_{3}$ and stratified $\mathrm{WO}_{3} / \mathrm{TiO}_{2}$ thin film and found that increase in degradation efficiency in stratified $\mathrm{WO}_{3} / \mathrm{TiO}_{2}$ thin films because of transfer of electron transferred from conduction band $\mathrm{TiO}_{2}$ to the conduction band $\mathrm{WO}_{3}$ and holes from valance band of $\mathrm{WO}_{3}$ to valance band of $\mathrm{TiO}_{2}$, thus minimizing the recombination of charge carriers. ${ }^{15}$

\section{Sonocatalytic technique}

Using the ultrasound and catalyst. Hunge et al., ${ }^{16}$ studied the sonocatalytic degradation of brilliant blue using $\mathrm{WO}_{3}$ and stratified $\mathrm{WO}_{3} / \mathrm{ZnO}$ photocatalyst. ${ }^{16}$

\section{Conclusions}

Advanced oxidation process proved to be effective way for the degradation of organic pollutants present into water sources. The photocatalytic efficiency depends upon the ability of catalyst (semiconductor) to generate electron hole pairs and therefor generate the hydroxyl and superoxide radicals.

\section{Acknowledgements}

Dr. YM Hunge is thankful to Science and Engineering Research Board, New Delhi, for the financial support and awarding National Postdoctoral Fellowship (N-PDF) award F. No. PDF/2017/000691. Dr. AA Yadav is thankful to Science and Engineering Research Board, New Delhi, for the financial support and awarding National Postdoctoral Fellowship (N-PDF) award F. No. PDF/2017/001419.

\section{References}

1. Hunge YM, Mohite VS, Kumbhar SS, ET AL. Photoelectrocatalytic degradation of methyl red using sprayed $\mathrm{WO}_{3}$ thin films under visible light irradiation. J Mater Sci Mater Electron. 2015;26(11):8404-8412.

2. Hunge YM. Photoelectrocatalytic degradation of methylene blue using spray deposited $\mathrm{ZnO}$ thin films under UV illumination. MOJ Poly Sci. 2017;1(4):00020.

3. Hunge YM. Sunlight assisted photoelectrocatalytic degradation of benzoic acid using stratified $\mathrm{WO}_{3} / \mathrm{TiO}_{2}$ thin films. Ceram Int. 2017;43:10089-10096.

4. Hunge YM, Yadav AA, Mohite BM, et al. Photoelectrocatalytic degradation of sugarcane factory wastewater using $\mathrm{WO}_{3} / \mathrm{ZnO}$ thin films. $J$ Mater Sci Mater Electron. 2018;29(6):3808-3816.

5. Hunge YM, Yadav AA, Mathe VL. Oxidative degradation of phthalic acid using $\mathrm{TiO}_{2}$ photocatalyst. J Mater Sci Mater Electron. 2018;29(8):6183-6187.

6. Fujishima A, Honda K. Electrochemical photolysis of water at a semiconductor electrode. Nature. 1972;238(5358):37-38.

7. Ali T, Hunge YM, Venkatraman A. UV assisted photoelectrocatalytic degradation of reactive red 152 dye using spray deposited $\mathrm{TiO}_{2}$ thin films. J Mater Sci Mater Electron. 2018;29(2):1209-1215.

8. Hunge YM, Yadav AA, Mahadik MA, et al. Degradation of organic dyes using spray deposited nanocrystalline stratified $\mathrm{WO}_{3} / \mathrm{TiO}_{2}$ photoelectrodes under sunlight illumination. Opt Mater. 2018;76:260-270.

9. Yang J, Wang D, Han H, et al. Roles of cocatalysts in photocatalysis and photoelectrocatalysis. Acc Chem Res. 2013;46(8):1900-9.

10. Hunge YM, Yadav AA, Mahadik MA, et al. A highly efficient visiblelight responsive sprayed $\mathrm{WO}_{3} / \mathrm{FTO}$ photoanode for photoelectrocatalytic degradation of brilliant blue. J Taiwan Inst Chem Eng. 2018;85:273-281.

11. Hunge YM, Yadav AA, Kulkarni SB, et al. A multifunctional ZnO thin film based devices for photoelectrocatalytic degradation of terephthalic acid and $\mathrm{CO}_{2}$ gas sensing applications. Sens Actuators B Chem. 2018;274:1-9.

12. Mohite VS, Mahadik MA, Kumbhar SS, et al. Photoelectrocatalytic degradation of benzoic acid using Au doped $\mathrm{TiO}_{2}$ thin films. J Photochem Photobiol. 2015;142:204-11.

13. Mahadik MA, Shinde SS, Hunge YM, et al. UV assisted photoelectrocatalytic oxidation of phthalic acid using spray deposited $\mathrm{Al}$ doped zinc oxide thin films. J Alloys Compd. 2014;611:446-451.

14. Huang BR, Lin TC, Liu YM. $\mathrm{WO}_{3} / \mathrm{TiO}_{2}$ core-shell nanostructure for high performance energy-saving smart windows. Sol Energy Mater Sol Cells. 2015;133:32-38.

15. Hunge YM, Mahadik MA, Moholkar AV, et al. Photoelectrocatalytic degradation of oxalic acid using $\mathrm{WO}_{3}$ and stratified $\mathrm{WO}_{3} / \mathrm{TiO}_{2}$ photocatalysts under sunlight illumination. Ultrason Sonochem. 2017;35:233-242.

16. Hunge YM, Yadav AA, Mathe VL. Ultrasound assisted synthesis of $\mathrm{WO}_{3}-\mathrm{ZnO}$ nanocomposites for brilliant blue dye degradation. Ultrason Sonochem. 2018;45:116-122.

\section{Conflict of interest}

None. 